\title{
Correlation of Sonographic Morphologic Index and CA-125 in Predicting the Nature of Ovarian Tumor
}

\section{Poonam Gusain ${ }^{1}$, *Suniti Joshi Rawal², Sharma Paudel ${ }^{3}$}

${ }^{1}$ Resident, ${ }^{2}$ Associate Professor, Department of Obstetrics and Gynecology, Tribhuvan University Teaching Hospital (TUTH), Maharajgunj, Kathmandu

${ }^{3}$ Associate Professor, Department of Radiology, TUTH, Maharajgunj, Kathmandu

\section{*Corresponding Author:}

\section{Dr. Suniti Joshi Rawal}

Email: sunudinurawal@yahoo.com

\section{ABSTRACT}

Introduction: Ovarian tumor is a group of disease that originates in the ovaries or in the related areas of the fallopian tubes and the peritoneum. Ovarian cancer causes more deaths than any other cancer of the female reproductive system. This study was undertaken to evaluate the efficacy of Sonographic Morphology Index (MI) and CA-125 levels in predicting malignancy in patients with ovarian tumors.

Methods: This study was conducted between April 2016 till April 2017 in the Department of Obstetrics and Gynaecology and Radiology of Tribhuvan University Teaching Hospital. During this period, 106 women with ovarian tumors fulfilling inclusion criteria were taken into the study. CA-125 levels measured and MI scoring was done. The diagnosis made with MI score and CA-125 score were then compared with histopathology report.

Results: Among the 106 studied cases $(\mathrm{N}=106), 88$ (83.01\%) had benign and $18(16.98 \%)$ had malignant ovarian tumors. Negative Predictive Value (NPV) and sensitivity of CA-125 for ovarian tumor was $94.10 \%$ and $77.77 \%$ respectively with accuracy of $73.58 \%$. Sensitivity and NPV of MI score was $100 \%$ with accuracy of $84.9 \%$ in predicting nature of ovarian tumors. Pearsons correlation coefficient was 0.216 which showed a positive correlation between MI and CA-125 in predicting nature of ovarian tumors.

Conclusion: The Sonographic MI system is an accurate and simple method to differentiate a malignant tumor from a benign ovarian tumor. The accuracy of the Sonographic MI system improved when the serum CA-125 level was also considered along.

Keywords: CA-125, Ovarian tumors, Sonographic Morphology Index

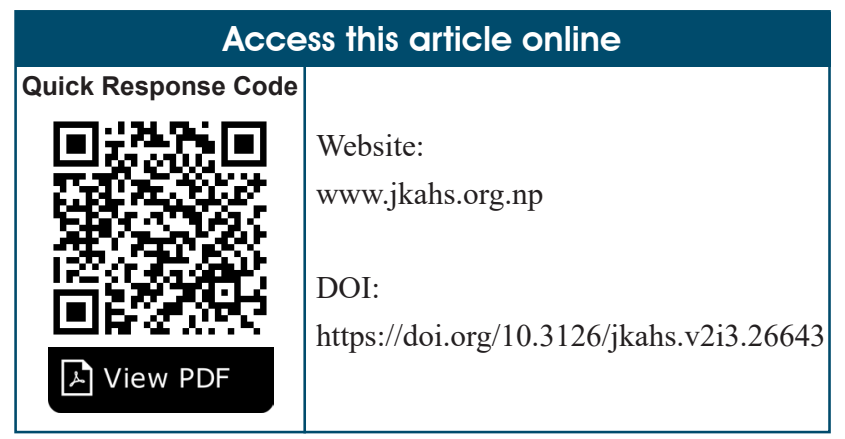

\section{Article Info.}

\section{How to cite this article?}

Gusain P, Rawal SJ, Paudel S. Correlation of Sonographic Morphologic Index and CA-125 in Predicting the Nature of Ovarian Tumor. Journal of Karnali Academy of Health Sciences. 2019;2(3): 166-170.

Received: 9 Oct., Accepted: 12 Nov., Published: 11 Dec. 2019

Conflict of Interest: None, Source of Support: None 


\section{INTRODUCTION}

Ovarian tumor constitute $23 \%^{1}$ of all gynecologic tumors with ovarian carcinoma being the seventh most common female cancer. ${ }^{2}$ Ovarian cancer is the 5th leading cause of deaths in women exceeded only by breast, lung, colon and uterine malignancies. ${ }^{3}$ More than $80 \%$ of patients who present with advanced disease have 5 year survival rates between $15 \%$ and $45 \%{ }^{4}$ In contrast the survival rate for stage I disease with malignancy confined to the ovary is around $95 \% .{ }^{4}$ Ovarian tumors are generally difficult to detect till they are in a clinically advanced stage or have attained a considerable large size to manifest symptoms. ${ }^{5}$ As a result there has been increased interest in development of methods that can detect ovarian cancer in early stage when it is curable.

CA-125 has been the most widely used biomarker to evaluate a woman with an ovarian tumor. ${ }^{7}$ It is a high molecular weight glycoprotein antigen expressed by coelomic epithelial lining cells and determined by monoclonal antibody. ${ }^{8}$ CA-125 is elevated in over $80 \%$ of patients with ovarian cancer. ${ }^{9}$ In most laboratories, the normal value is 0 to 35 units $/ \mathrm{ml}$. Morphological Index (MI) js based on the real time ultrasound and detects altered ovarian morphology. De Priest et $\mathrm{al}^{10}$ in 1993 developed Morphology Index (MI) based on morphologic characteristics of ovarian tumors. Studies have concluded that a combined strategy of imaging with biomarker was superior to either one alone. ${ }^{7}$ When CA-125 and ultrasonography were considered together, specificity increased to $99.8 \%$.

This study was conducted to evaluate the efficacy of Sonographic Morphology Index (MI) and CA125 levels in predicting malignancy in patients with ovarian tumors so that frequent use of CT scans could be avoided in a low resource setting and help in better management and survival.

\section{MATERIALS AND METHODS}

This was a prospective study done in Department of Obstetrics and Gynecology and Radiology, Tribhuwan
University Teaching Hospital, Kathmandu Nepal, from 13 ${ }^{\text {th }}$ April 2016 till 12 ${ }^{\text {th }}$ April 2017. Approval of the study was taken from Institutional Review Board of Institute of Medicine, Research Department. Purposive sampling was done and sample size of $100 \pm$ 10 was calculated based on statistics of previous year.

All women with ovarian tumor irrespective of age and menopausal status undergoing surgery in the research institute were included in the study. Any known case of ovarian carcinoma or already operated for ovarian carcinoma, any other adnexal mass other than ovarian pathology, dermoid or germ cell tumor confirmed by histopathology, when CA-125 levels were not available preoperatively or when MI score couldnot be calculated were excluded from the study.

Patients admitted in Female Surgical ward with a diagnosis of ovarian tumor were taken into account every day and history and socio demographic profile of the cases were documented. Patients were counseled as to the implications and limitations of such investigation. An informed consent was obtained from all patients and only those patients who gave consent were included in the study. CA-125 levels were measured preoperatively in all women admitted in ward with a diagnosis of ovarian tumor. CA-125 level $<35$ units $/ \mathrm{ml}$ were labeled as benign and $\geq 35$ units $/ \mathrm{ml}$ were labeled as malignant.

The patients were then subjected to ultrasound and three dimensional size and structure of ovarian tumor was noted. Volume of ovarian tumor was calculated by Prolate ellipsoid formula (Volume of ovarian tumor $=$ length $\times$ width $\times$ height $\times 0.523$ ).

MI score was calculated by adding volume score ( Table 1) and structure score (Table 2). MI score $<5$ was labelled benign $\& \geq 5$ was labelled malignant. At the end MI score and CA-125 level were compared with histopathology report. Sensitivity, specificity, Negative Predictive Value, Positive Predictive Value and accuracy were calculated each for CA-125 \& MI score. Chi-square (x2) test was used. Confidence interval of $95 \%$ was taken and $\mathrm{P}$ value of $<0.05$ was regarded as statistically significant. 
Table 1: Morphological Index Scoring system for tumor volume

\begin{tabular}{cc}
\hline \hline Score & Tumor Volume (cc) \\
\hline 0 & $<10 \mathrm{cc}$ \\
1 & $\geq 10-50 \mathrm{cc}$ \\
2 & $>50-100 \mathrm{cc}$ \\
3 & $>100-200 \mathrm{cc}$ \\
4 & $>200-500 \mathrm{cc}$ \\
5 & $>500 \mathrm{cc}$ \\
\hline
\end{tabular}

Table 2: Morphological Index Scoring system for tumor structure

\begin{tabular}{cl}
\hline \hline Score & \multicolumn{1}{c}{ Tumor Structure } \\
\hline 0 & Smooth wall, sonolucent \\
1 & Smooth wall, diffuse echogenicity \\
2 & Wall thickening, $<3 \mathrm{~mm}$ fine septa \\
3 & Papillary projection, $>3 \mathrm{~mm}$ \\
4 & Complex cyst with predominantly solid \\
& component \\
5 & Complex cyst with solid cystic areas with \\
& extratumoral fluid \\
\hline
\end{tabular}

\section{RESULTS}

During the study period, there were a total of 145 ovarian tumor cases at TUTH, out of which 106 (73.1\%) were included and 39 (26.89\%) were excluded from the study. Among 106 cases 88 (83.01\%) were benign and 18 (16.98\%) were malignant. Out of 39 excluded cases, 34 cases were teratoma, 2 cases of paratubal cyst, 2 cases of germ cell tumor and 1 was a known case of ovarian tumor.

The most common benign tumor was endometriotic cyst $(\mathrm{N}=32,36.36 \%)$ followed by serous cystadenoma
$(\mathrm{N}=22,25 \%)$.Out of 18 malignant tumors, maximum $14(77.77 \%)$ were mucinous cystadenocarcinoma.

Table 3: Results of serum CA-125

\begin{tabular}{|c|c|c|c|}
\hline CA-125 levels & $\begin{array}{l}\text { Total } \\
\text { Cases }\end{array}$ & Benign & Malignan \\
\hline$<35$ units $/ \mathrm{ml}$ & 68 & $\begin{array}{c}64 \\
(94.11 \%)\end{array}$ & $\begin{array}{c}4 \\
(5.8 \%)\end{array}$ \\
\hline$\geq 35$ units $/ \mathrm{ml}$ & 38 & $\begin{array}{c}24 \\
(63.15 \%) \\
\end{array}$ & $\begin{array}{c}14 \\
(36.84 \%)\end{array}$ \\
\hline Total Cases & 106 & 88 & 18 \\
\hline
\end{tabular}

Of 68 cases whose CA-125 levels were $<35$ units/ $\mathrm{ml}, 64(94.11 \%)$ were benign and 4 (5.4\%) were malignant. Fourteen $(36.78 \%)$ cases were malignant whose CA-125 levels were $\geq 35$ units $/ \mathrm{ml}$.

Table 4: Statistical parameters associated with CA-125

\begin{tabular}{lccc}
\hline & $\begin{array}{c}\text { Test positive } \\
\text { (CA-125 } \geq \\
\text { 35units/ml) }\end{array}$ & $\begin{array}{c}\text { Test negative } \\
\text { (CA-125 }< \\
\text { 35units/ml) }\end{array}$ & Total \\
\hline $\begin{array}{l}\text { Disease } \\
\text { positive } \\
\text { (malignant) }\end{array}$ & 14 & 4 & 18 \\
$\begin{array}{l}\text { Disease } \\
\text { negative }\end{array}$ & & & \\
(benign) & 24 & 64 & 88 \\
\hline Total & $\mathbf{3 8}$ & $\mathbf{6 8}$ & $\mathbf{1 0 6}$ \\
\hline Sensitivity & $\mathrm{TP} / \mathrm{TP}+\mathrm{FN}$ & 0.777 \\
Specificity & $\mathrm{TN} / \mathrm{TN}+\mathrm{FP}$ & 0.727 \\
$\quad$ PPV & $\mathrm{TP} / \mathrm{TP}+\mathrm{FP}$ & 0.368 \\
$\quad \mathrm{NPV}$ & $\mathrm{TN} / \mathrm{TN}+\mathrm{FN}$ & 0.941 \\
Accuracy & $\mathrm{TP}+\mathrm{TN} / \mathrm{TP}+\mathrm{TN}+\mathrm{FN}+\mathrm{FP}$ & 0.735 \\
\hline$P-v a t y$
\end{tabular}

$P$-value for CA-125 was $<0.001$.

\section{Table 5: Structure score of ovarian tumors}

\begin{tabular}{lcccc}
\hline \multicolumn{1}{c}{ Ovarian tumor structure } & $\begin{array}{c}\text { Structure } \\
\text { score }\end{array}$ & $\begin{array}{c}\text { Total number of } \\
\text { ovarian tumor (106) }\end{array}$ & Benign & Malignant \\
\hline Smooth wall + sonulucent & 0 & 16 & $16(100 \%)$ & 0 \\
Smooth wall, diffuse echogenicity & 1 & 37 & $37(100 \%)$ & 0 \\
Wall thickening, $<3$ mm fine septa & 2 & 34 & $32(94.11 \%)$ & $2(5.8 \%)$ \\
Papillary projection, $>3 \mathrm{~mm}$ & 3 & 6 & $2(33.33 \%)$ & $4(66.66 \%)$ \\
Complex cyst, predominantly solid component & 4 & 7 & $1(14.28 \%)$ & $6(85.71 \%)$ \\
Complex cyst, solid areas, extratumoral fluid & 5 & 6 & 0 & $6(100 \%)$ \\
\hline
\end{tabular}


Sixteen (100\%) ovarian tumors with smooth wall and sonolucent echogenecity and 37 (100\%) with diffuse echogenicity were all benign in nature. Complex ovarian tumors $(\mathrm{N}=6,100 \%)$ with solid areas and extratumural fluid were $100 \%$ malignant.

Table 6: Statistical parameters associated with MI score $\geq 5$ predictive of ovarian malignancy.

\begin{tabular}{lccc}
\hline & $\begin{array}{c}\text { Test positive } \\
(\mathbf{M I} \geq \mathbf{5})\end{array}$ & $\begin{array}{c}\text { Test negative } \\
(\mathbf{M I}<\mathbf{5})\end{array}$ & Total \\
\hline $\begin{array}{l}\text { Disease } \\
\text { positive } \\
\text { (malignant) }\end{array}$ & 18 & 0 & 18 \\
$\begin{array}{l}\text { Disease } \\
\text { negative } \\
\text { (benign) }\end{array}$ & 16 & 72 & 88 \\
\hline Total & & & \\
\hline Sensitivity & $\mathbf{3 4}$ & $\mathbf{1 0 6}$ \\
Specificity & $\mathrm{TP} / \mathrm{TP}+\mathrm{FN}$ & 1.000 \\
\multicolumn{1}{c}{$\mathrm{TN} / \mathrm{TN}+\mathrm{FP}$} & 0.818 \\
$\quad \mathrm{NPV}$ & $\mathrm{TP} / \mathrm{TP}+\mathrm{FP}$ & 0.529 \\
Accuracy & $\mathrm{TP}+\mathrm{TN} / \mathrm{TP}+\mathrm{TN}+\mathrm{FN}+\mathrm{FP}$ & 0.849 \\
\hline
\end{tabular}

$P$ value for MI was 0.001

\section{DISCUSSION}

In our study with a cut off value of 35 units $/ \mathrm{ml}$, the sensitivity, specificity, PPV and NPV of CA-125 were $0.777,0.727,0.368,0.941$ respectively. Similar finding was noted by Olivier et al. ${ }^{11}$ and by Morgante et al. ${ }^{12}$ In this study ovarian tumors having smooth wall and sonulucent or diffuse echogenicity were $100 \%$ (N=16 and $\mathrm{N}=37$ respectively) benign in nature. Complex ovarian tumors with solid areas and extratumoral fluid were $100 \%(\mathrm{~N}=6)$ malignant though one out of seven (14.28\%) ovarian tumors with complex structure and predominantly solid component was histologically benign. Around $66.66 \%$ (4) of tumors with papillary projection $(>3 \mathrm{~mm})$ were malignant. This implies that papillary projection $>3 \mathrm{~mm}$ is an important feature of malignancy.

Our finding is consistent with study done by Ueland et $\mathrm{al}^{6}$ where $100 \%$ of ovarian tumors having smooth wall and sonulucent echogenicity were benign and
$98 \%$ with diffuse echogenicity were benign. Ovarian tumors with fine papillary projection $<3 \mathrm{~mm}$ were benign $(32,94 \%)$ in index study, finding that was similar to study done by Ueland et $\mathrm{al}^{6}$ reporting $95 \%$ cases to be benign.

In the index study ovarian tumors having MI score $\leq$ 5 , were all benign and tumors having MI score 9 or 10 were all malignant. Tumors with MI score 6 or 7 had $50 \%$ benign and $50 \%$ malignant tumors. These results were similar to a study done by DePriest et al. ${ }^{10}$ in which $80(100 \%)$ tumors having MI score $<5$ were all benign and 13 (32\%) of cases having MI $\geq 5$ had ovarian cancer.

In the present study sensitivity, specificity, PPV, NPV and accuracy of MI score for predicting malignancy in ovarian tumors was $1.00,0.818,0.529,1.00$ and 0.849 respectively. Similar results were observed by Sassoneet al. ${ }^{13,14}$

\section{CONCLUSION}

This study shows that the Sonographic Morphologic Index has high efficacy in predicting the nature of ovarian tumors as compared with CA-125 with an accuracy of $84.9 \%$ and NPV $100 \%$ as compared with CA- 125 .

\section{REFERENCES}

1. Merino MJ, Jaffe G. Age contrast in ovarian pathology. Cancer. 1993;71(S2):537-44. http:// dx.doi.org/10.1002/cncr.2820710208

2. Forae GD, Aligbe JU. Ovarian tumors among Nigerian females: A private practice experience in Benin-City, Nigeria. Advanced biomedical research. 2016;5. https://doi.org/10.4103/22779175.179183

3. Torre LA, Bray F, Siegel RL, Ferlay J, LortetTieulent J, Jemal A. Global cancer statistics, 2012. CA: a cancer journal for clinicians. 2015;65(2):87108. https://doi.org/10.3322/caac.21262

4. Nossov V, Amneus M, Su F, Lang J, Janco JMT, Reddy ST, et al. The early detection of ovarian cancer: from traditional methods to proteomics. Can we really do better than serum CA-125? American journal of obstetrics and gynecology. 2008;199(3):215-23. https://doi.org/10.1016/j. ajog.2008.04.009 
5. Jacobs IJ, Menon U. Progress and challenges in screening for early detection of ovarian cancer. Molecular \& Cellular Proteomics. 2004;3(4):355-66. https://doi.org/10.1074/mcp.R400006-MCP200

6. Ueland F, DePriest P, Pavlik E, Kryscio R, Van Nagell J. Preoperative differentiation of malignant from benign ovarian tumors: the efficacy of morphology indexing and Doppler flow sonography. Gynecologic oncology. 2003;91(1):46-50. https://doi.org/10.1016/S0090-8258(03)00414-1

7. Goodrich ST, Bristow RE, Santoso JT, Miller RW, Smith A, Zhang Z, et al. The effect of ovarian imaging on the clinical interpretation of a multivariate index assay. American Journal of Obstetrics and Gynecology.2014;211(1):65.e1-. e11. https://doi.org/10.1016/j.ajog.2014.02.010

8. Leelahakorn S, Tangjitgamol S, Manusirivithaya S, Thongsuksai P, Jaroenchainon P, Jivangkul C. Comparison of ultrasound score, CA125, menopausal status, and risk of malignancy index in differentiating between benign and borderline or malignant ovarian tumors. Journal of Medical Assiciation of Thailand. 2005;88:S22.

9. Jeoung HY, Choi HS, Lim YS, Lee MY, Kim SA, Han SJ, et al. The efficacy of sonographic morphology indexing and serum CA-125 for preoperative differentiation of malignant from benign ovarian tumors in patients after operation with ovarian tumors. Journal of gynecologic oncology. 2008;19(4):229-35. https://dx.doi.org/10.3802\%2Fjgo.2008.19.4.229
10. DePriest P, Shenson D, Fried A, Hunter J, Andrews S, Gallion H, et al. A morphology index based on sonographic findings in ovarian cancer. Gynecologic Oncology. 1993;51(1):711. https://doi.org/10.1006/gyno.1993.1238

11. Olivier R, Lubsen-Brandsma M, Verhoef S, Van Beurden M. CA125 and transvaginal ultrasound monitoring in high-risk women cannot prevent the diagnosis of advanced ovarian cancer. Gynecologic oncology. 2006;100(1):20-6. https://doi.org/10.1016/j.ygyno.2005.08.038

12. Morgante G, Marca A, Ditto A, Leo V. Comparison of two malignancy risk indices based on serum CA125, ultrasound score and menopausal status in the diagnosis of ovarian masses. BJOG: An International Journal of Obstetrics \& Gynaecology. 1999;106(6):524-7.

13. Skates SJ, Menon U, MacDonald N, Rosenthal AN, Oram DH, Knapp RC, et al. Calculation of the risk of ovarian cancer from serial CA-125 values for preclinical detection in postmenopausal women. Journal of clinical oncology: official journal of the American Society of Clinical Oncology. 2003;21(10 Suppl):206s-10s. https:// doi.org/10.1200/JCO.2003.02.955

14. Pradhan R, Pant U, Aryal B. Efficiency of HPV DNA test Verses Pap Smear in the screening of cervical cancer. JKAHS [Internet]. 6Oct.2018 [cited 11Dec.2019];1(02):9-3. Available from: https://jkahs.org.np/jkahs/index.php/jkahs/ article/view/3 